Águas Subterrâneas (2016) 30(1): 1-17.

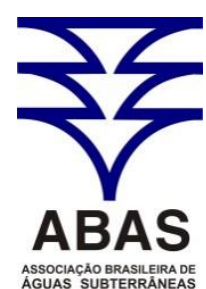

www.abas.org

\section{ANÁLISE EXPLORATÓRIA DE DADOS DA CONDUTIVIDADE ELÉTRICA NAS ÁGUAS DO SISTEMA AQUÍFERO SERRA GERAL NO RIO GRANDE DO SUL E SANTA CATARINA}

\author{
EXPLORATORY DATA ANALYSIS OF ELECTRIC CONDUCTIVITY OF \\ WATER IN THE SERRA GERAL AQUIFER SYSTEM IN THE RIO \\ GRANDE DO SUL AND SANTA CATARINA STATES, BRAZIL
}

Artigo recebido em: 22/10/2015 e aceito para publicação em: 13/02/2016.

DOI: http://dx.doi.org/10.14295/ras.v30i1.28518

\begin{abstract}
Resumo: A técnica estatística de Análise Exploratória de Dados (AED) foi aplicada a 7.620 medidas de campo de condutividade elétrica nas águas do Sistema Aquífero Serra Geral no Rio Grande do Sul e em Santa Catarina e identificou quatro classes. Valores de condutividade elétrica superiores a 378,35 $\mu \mathrm{S} / \mathrm{cm}$ são anômalos, enquanto o intervalo de background está compreendido entre 117,35 e 378,35 $\mathrm{S} / \mathrm{cm}$. A avaliação hidroquímica realizada em 356 análises fisico-químicas, nas quatro classes determinadas pela análise exploratória, demonstrou uma evidente separação conforme a evolução geoquímica dessas águas. A classe dos valores mais elevados (C1), está relacionada às águas mais antigas e apresenta íntima relação com as estruturas regionais, como zonas de falhas e grandes lineamentos. Localmente há recarga ascendente, misturando águas do aquífero fraturado com as águas dos aquíferos sotopostos (Sistema Aquífero Guarani e Aquíferos Permianos). As classes C2 e C3 representam as águas típicas do Sistema Aquífero Serra Geral e sua variação deve-se, provavelmente, a diferentes tempos de residência. A classe C4, de menores valores, refere-se às águas mais jovens, que infiltraram no aquífero por recarga meteórica através do manto de alteração das rochas vulcânicas.
\end{abstract}

Palavras chave: Sistema Aquífero Serra Geral. Condutividade elétrica. Análise exploratória de dados. Hidroquímica

\begin{abstract}
The Exploratory Data Analysis (EDA) technique applied to electrical conductivity field measures in 7,620 groundwater samples of the Serra Geral aquifer system in Rio Grande do Sul and Santa Catarina States has revealed four distinct classes. The values above $378.35 \mu \mathrm{S} / \mathrm{cm}$ were considered anomalous and represent the $\mathrm{C} 1 \mathrm{class}$. Electrical conductivities between 117.35 and $378.35 \mu \mathrm{S} / \mathrm{cm}$ are background values. A physical-chemical analysis conducted at 356 well water samples across the various classes determined by exploratory analysis has shown different hydrochemical evolution paths within the Serra Geral Aquifer System. The class bearing the higher values of electrical conductivity represents the oldest waters with strong relationship with regional structures, such as fault zones and large lineaments. Locally there are mixture through ascending recharge with water from porous aquifers (Guarani Aquifer System and Permian aquifers). The C2 and C3 classes are considered to be the typical water for this aquifer system and slight variations are probably due to the different residence times. Water samples belonging to the $\mathrm{C} 4 \mathrm{class}$ represent younger waters recently infiltrated by the meteoric recharge through the weathering zone of volcanic rocks.
\end{abstract}

Keywords: Serra Geral Aquifer System. Electrical conductivity. Exploratory data analysis. Hydrochemical.

\section{INTRODUÇÃO}

O sistema aquífero de maior abrangência e mais utilizado na região Sul do Brasil é o Sistema Aquífero Serra Geral (SASG), de natureza fraturada, constituído pelas descontinuidades presentes nas rochas vulcânicas do Grupo Serra Geral. Tais rochas afloram em praticamente toda a Bacia do
Paraná (Figura 1) e possuem uma grande importância hidrogeológica decorrente da sua elevada explotabilidade. Suas águas são exploradas através de poços tubulares e captações de fontes, com vazões de até 220 $\mathrm{m}^{3} / \mathrm{h}$ (Rebouças e Fraga, 1988; Freitas et al., 2002), sendo usadas para consumo humano, industrial, pastoril e também para balneabilidade.

1 e 3 CPRM - Serviço Geológico do Brasil (marcos.freitas@cprm.gov.br, jose.andriotti@,cprm.gov.br)

2 Instituto de Geociências da Universidade Federal do Rio Grande do Sul (ari.roisenberg@ufras.br) 


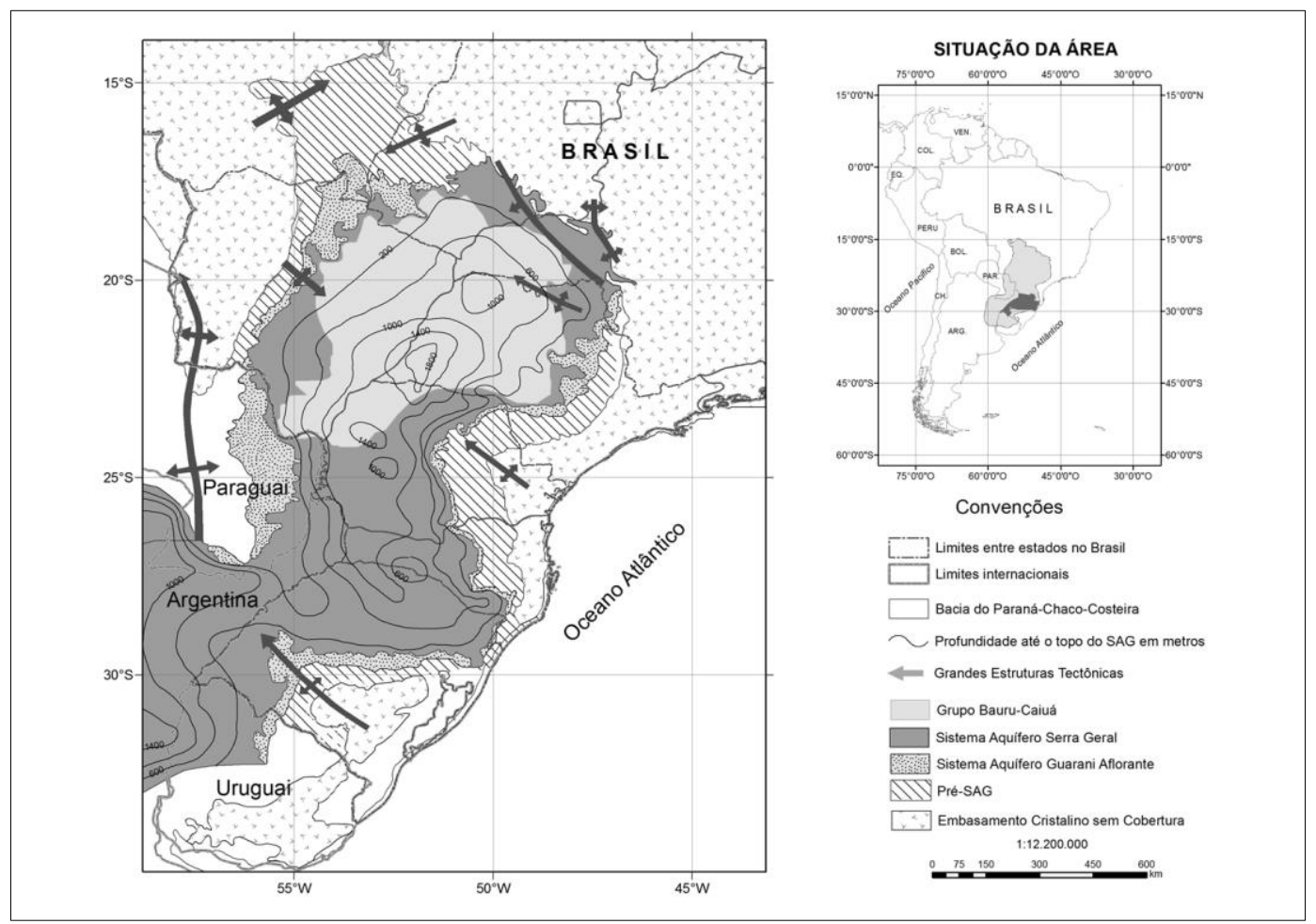

Figura 1 - Mapa de localização da área e contexto geotectônico regional da Bacia do Paraná (modificado de Machado, 2005)

Figure 1 - Location map of the study area and regional geotectonic structures of the Paraná Basin (modified from Machado, 2005)

Levantamentos junto ao Sistema de Informações de Águas Subterrâneas (SIAGAS), da CPRM - Serviço Geológico do Brasil, ilustram a magnitude e a importância deste sistema aquífero nos Estados do Rio Grande do Sul e Santa Catarina. O SIAGAS registra 10.500 poços tubulares que captam exclusivamente água do SASG, dos quais $74 \%$ encontram-se em funcionamento para abastecimento público, industrial e dessedentação de animais. Considerando a vazão média dos poços em utilização, que é de $11,16 \mathrm{~m}^{3} / \mathrm{h}$, e um período de bombeamento de 12 horas diárias, estima-se uma retirada anual de água do SASG de cerca de 380 milhões de metros cúbicos.

As características hidroquímicas do SASG têm sido definidas através de metodologias clássicas de tratamento de dados em análises químicas de cátions e ânions maiores, entre outros, utilizando diagramas hidroquímicos, por vários autores dentre os quais Fraga (1986); Rebouças e Fraga (1988); Lisboa (1996); Freitas e Machado (2000); Freitas et al. (2002); Regi- nato e Strieder (2006); Nanni (2008); Freitas et al. (2011); Freitas et al. (2012); Reginato et al. (2013). O SASG, no entanto, ainda carece de maior entendimento, havendo a necessidade de estudos básicos para a compreensão da sua dinâmica, recarga, descarga, interação com outros sistemas aquíferos e sua reação aos fatores antrópicos, como superexplotação e contaminação.

O objetivo deste trabalho reside na determinação das anomalias da condutividade elétrica (CE) das águas do SASG, utilizando a técnica de Análise Exploratória de Dados (EDA - Exploratory Data Analysis), definida por Tukey (1977), aplicada para 7.620 medidas de campo realizadas pelo Serviço Geológico do Brasil nos poços tubulares que captam exclusivamente o SASG no Rio Grande do Sul e em Santa Catarina. O método de trabalho também permite identificar regionalmente onde ocorrem os valores anômalos das águas do SASG, bem como tecer breves considerações sobre sua tipologia hidrogeoquímica. 


\section{CONTEXTO GEOLÓGICO E ESTRU- TURAL}

O SASG desenvolve-se nas rochas vulcânicas cretáceas de composição básica e ácida do Grupo Serra Geral (Wildner et al., 2009) que têm continuidade com o pacote aflorante em Etendeka, Namíbia, configurando uma das maiores exposições de províncias vulcânicas continentais do planeta. As rochas associadas ao Grupo Serra Geral ocorrem em quase toda a área da Bacia do Paraná, cerca de $900.000 \mathrm{~km}^{2}$, abrangendo a região sul, parte do sudeste e centroeste do Brasil, além de parte do Paraguai, Argentina e Uruguai.

A estruturação tectônica da Bacia do Paraná vem sendo objeto de muitos estudos voltados principalmente à prospecção de hidrocarbonetos, que utilizam técnicas de sensoriamento remoto, levantamentos geofísicos e de geologia estrutural (ASMUS, 1975; SOARES et al., 1982; ZALÁN et al., 1986; SOARES et al., 2008).

Zalán et al. (1991), em uma abordagem sobre a evolução geológica da bacia, descreve regionalmente seu arranjo estrutural, que apresenta um marcante padrão de feições lineares que se cruzam. Tais feições são divididas pelos autores em três grupos, de acordo com suas orientações (NW-SE, NESW e E-W). As direções NW-SE e NE-SW são as orientações mais importantes e podem representar falhas simples ou zonas de falhas extensas, com centenas de quilômetros de comprimento e algumas poucas dezenas de quilômetros de largura. Segundo os autores, são antigas zonas de fraqueza do Embasamento Cristalino que foram reativadas durante o processo de evolução da bacia.

Soares et al. (1982) também reconhecem o padrão de direções NW e NE, através de estudo detalhado de imagens LANDSAT e de radar nas porções central e oriental da bacia. Identificaram faixas retilíneas com alta concentração de lineamentos separados em três grupos direcionais NW (variando de $\mathrm{N} 25^{\circ} \mathrm{W}$ a $\mathrm{N} 65^{\circ} \mathrm{W}$ ) e dois grupos de $\mathrm{NE}$ (variando entre $\mathrm{N} 35^{\circ} \mathrm{E}$ e $\mathrm{N} 60^{\circ} \mathrm{E}$ ). Conforme estes autores, tais zonas estruturais representam áreas de maior mobilidade tectônica em comparação com as áreas adjacentes. Também concluíram que esses elementos representam zonas de fraqueza do embasamento, onde as direções NW estão intensivamente intrudidas por diques básicos, enquanto as direções NE não apresentam estas feições. O padrão estrutural das zonas de falha NE é diferente, pois elas são constituídas ou por uma única falha larga ou por uma zona de falha retilínea (exceção das zonas de falha Lancinha-Cubatão e Transbrasiliano), geralmente sem a presença de diques (ZALÁN et al., 1990). No entanto, as estruturas relacionadas às movimentações transcorrentes são muito mais comuns ao longo dos lineamentos de direção NE. Os movimentos ao longo das estruturas tiveram componentes horizontais e verticais, com os blocos por elas delineados, movimentando-se para cima e para baixo, em um estilo estrutural típico de falhas verticais. Os rejeitos verticais alcançam algumas centenas de metros.

Freitas et al. (2002), em estudo sobre lineamentos estruturais realizado na escala 1:250.000 na região oeste de Santa Catarina, destacam as direções $\mathrm{N} 30^{\circ}-50^{\circ} \mathrm{E}$ e $\mathrm{N} 40^{\circ}$ $60^{\circ} \mathrm{W}$ como principais e as direções N-S e E$\mathrm{W}$ como secundárias. Também mencionam falhas verticais de direção $\mathrm{N} 70^{\circ} \mathrm{E}$ com $135 \mathrm{~km}$ de extensão e prováveis falhas N-S com fontes hipotermais associadas, na Bacia Hidrográfica do Rio das Antas.

Soares et al. (2008) comparam os lineamentos da Bacia do Paraná interpretados e traçados a partir de diversas fontes (sensoriamento remoto e geofísica) e concluem que há um alto índice de concordância para as direções NW e NE, enquanto que nas direções NNE, NNW, E-W e N-S os índices são baixos. Estes autores também descrevem uma forte compartimentação estrutural na bacia com blocos limitados por falhas com rejeitos na ordem de 100 metros.

Machado et al. (2012) mostram o resultado de um estudo multiescalar de lineamentos estruturais na borda leste da Bacia do Paraná em Santa Catarina, associados a estudos estruturais em pedreiras 
de rochas alcalinas na região do Domo de Lages. Segundo os autores há correlação entre fotolineamentos extraídos e falhas analisadas nas pedreiras, com destaque para as direções N-S (NNE a NNW) e E-W (ENE a ESE), que correspondem a falhas transcorrentes destrais e sinistrais, respec-tivamente. Em segundo plano ocorreriam as direções NE e NW. Tais estruturas são reativações do embasamento associadas a um campo de tensão $\sigma_{1}$ orientado segundo NE-SW com idade entre o Eocretáeo e o Terciário.

Philipp et al. (2014) apresentam os resultados de modelagem de dados magnetotelúricos e análise integrada com informações geológicas, estruturais e geofísicas na caracterização de estruturas de abertura (rifting, estratigrafia e intrusões na porção sulsudeste da Bacia do Paraná. Estes autores propõem vários falhamentos de direções NWSE e NE-SW, corroborados por dados de geofísica em três seções regionais de dados magnetotelúricos.

\section{CONTEXTO HIDROGEOLÓGICO}

O SASG caracteriza-se pela capacidade de armazenamento e de circulação da água relacionados à presença de juntas e fraturas, ampliada por suas zonas vesiculares e amigdaloidais, de topo de derrame e zonas de disjunção horizontal. Tais estruturas, quando interceptadas por fraturas e falhas, interconectam-se podendo armazenar e transmitir grandes volumes de água subterrânea (FREITAS et al., 2002). O SASG confina os aquíferos de natureza sedimentar como o Sistema Aquífero Guarani/SAG (Araújo et al., 1995) e sistemas aquíferos mais profundos de idade permiana (Pré-SAG). O mecanismo de recarga do SASG e sua interação com o SAG e os aquíferos permianos, dependem da presença de estruturas tectônicas e das cargas hidráulicas envolvidas. A Figura 2 ilustra o mecanismo de recarga meteórica e recarga ascendente, além da mistura de águas entre os sistemas aquíferos.

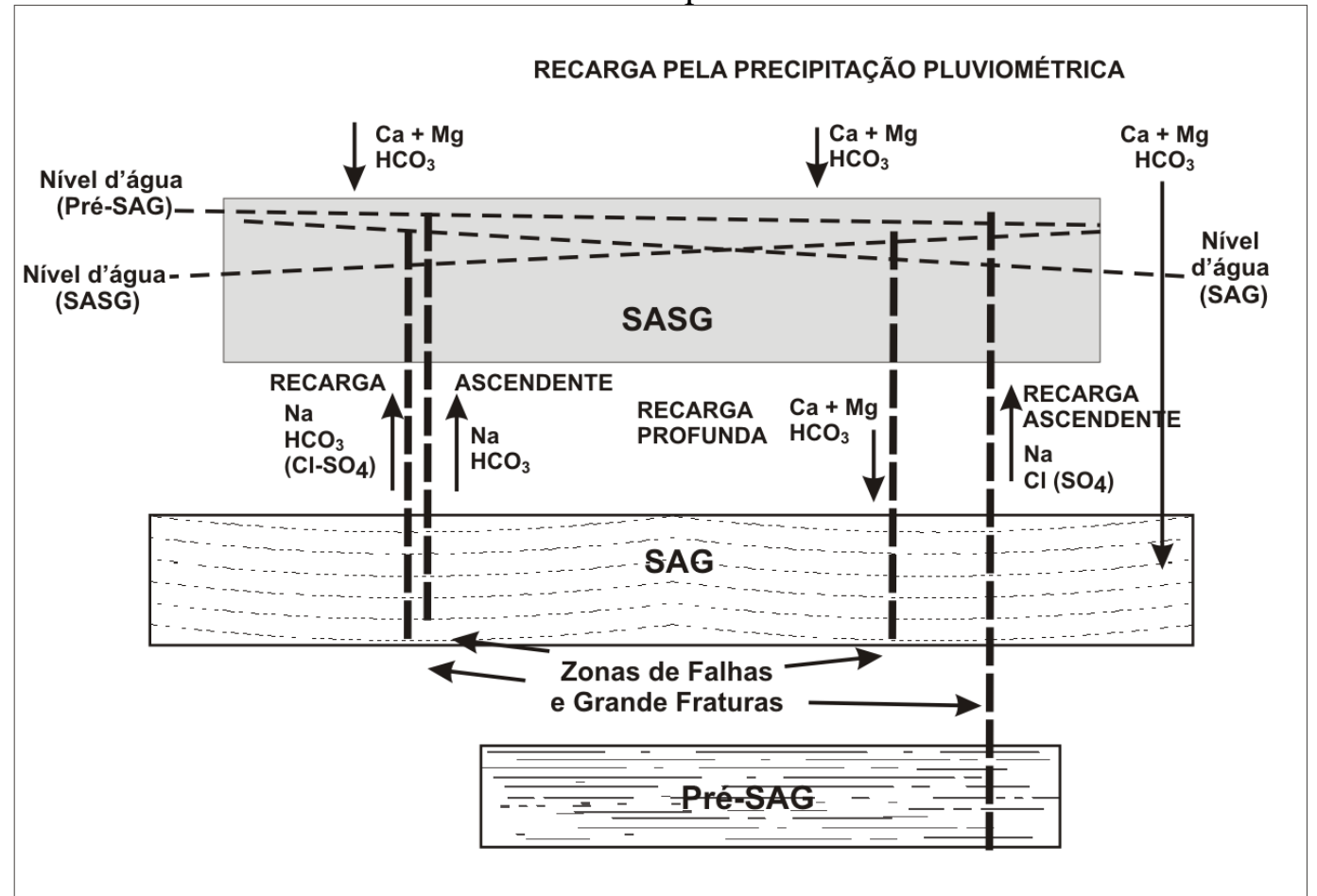

Figura 2 - Modelo conceitual dos mecanismos de recarga do SASG, sua relação com os aquíferos SAG e Pré-SAG (aquíferos permianos), bem como os tipos hidrogeoquímicos resultantes (Modificado de Machado e Freitas, 2000)

Figure 2 - Conceptual model of the SGAS recharge mechanisms, its relationship with the GAS and permian aquifers as well as the resulting hydrogeochemical types (Modified from Machado and Freitas, 2000) 
Pelas suas características hidrogeológicas e grande área de ocorrência, o SASG representa o principal recurso hídrico subterrâneo na região sul do Brasil, possibilitando a captação de água subterrânea a um custo reduzido, em geral, suprindo satisfatoriamente as comunidades rurais, indústrias e até sedes de pequenos municípios. $\mathrm{Na}$ área de estudo, que engloba a ocorrência do SASG nos Estados do Rio Grande do Sul e Santa Catarina, os poços tubulares que captam o aquífero fraturado apresentam profundidade máxima de 474 metros e valores médios de 114,4 metros. As vazões são muito variáveis e atingem até $138,46 \mathrm{~m}^{3} / \mathrm{h}$ (poço G.1055-I6 da CORSAN em Ibirubá, RS com 90 metros de profundidade), com média e mediana de 11,18 e $7,90 \mathrm{~m}^{3} / \mathrm{h}$, respectivamente.

As rochas fraturadas do Grupo Serra Geral configuram-se como aquíferos livres, podendo, em casos particulares, desenvolver condições de aquífero confinado (HAUSMAN, 1995). Freitas et al. (2002) citam vários casos de poços jorrantes, alguns deles com vazões livres consideráveis e, localmente, com termalismo associado.

Lisboa (1996) em um amplo estudo da hidrogeoquímica e seus controladores geológicos nas unidades hidrogeológicas do SASG no Rio Grande do Sul, conclui que este sistema está condicionado por três unidades morfotectônicas: Fachada Atlântica, Abóbada Oeste e Abóbada Central, divididas em subunidades conforme o grau de disse-cação do relevo. Menciona que o aumento do $\mathrm{pH}$ e dos sólidos totais na Subunidade Hidrogeológica Efusivas Básicas da Abóbada Central Densamente Dissecada é diretamente proporcional à profundidade de entrada de água nos poços, o que indicaria influência dos arenitos sotopostos.

Reginato e Strieder (2006) caracterizaram quimicamente as águas subterrâneas do SASG na região nordeste do Rio Grande do Sul e em parte da Bacia Hidrográfica Taquari-Antas. As águas bicarbonatadas cálcicas ou magnesianas possuem um controle litoquímico e estão relacionadas com os processos de intemperismo que atuam sobre as rochas vulcânicas da região. Segundo os mesmos autores, as águas bicarbonatadas sódicas e sulfatadas cálcicas ou magnesianas evidenciam a existência de condicionadores geotectônicos e morfotec-tônicos que seriam responsáveis pela liga-ção, circulação e consequente mistura das águas (SAG e SASG).

Betiollo (2006) em estudo de tectônica rúptil na região nordeste do Estado do Rio Grande do Sul define padrões direcionais que controlam a hidrogeoquímica do SASG, com predominância de águas com baixo conteúdo iônico relacionadas à recarga meteórica, mas cita em determinadas áreas relações com lineamentos de médio porte e ascensão de águas do SAG para o SASG.

Nanni (2008) demonstra através de análise tectônica a relação entre as fácies hidroquímicas no SASG do Rio Grande do Sul e o controle regional de fraturas. Também menciona que a dinâmica da recarga ascendente dos sistemas aquíferos sotopostos pode gerar concentrações anômalas de fluoreto no mesmo.

Freitas et al. (2012) separam o SASG no noroeste do Rio Grande do Sul em quatro domínios hidrogeológicos onde a melhor zona atinge vazões de até $80 \mathrm{~m}^{3} / \mathrm{h}$. Os tipos hidrogeoquímicos principais identificados contemplam águas bicarbonatadas cálcicas ou magnesianas e águas bicarbonatadas sódicas. As primeiras estão relacionadas à recarga meteórica através do solo ou manto de alteração e o segundo tipo refere-se, segundo os autores, à mistura com as águas do SAG.

Reginato et al. (2013) menciona que o SASG na região nordeste do Rio Grande do Sul geralmente apresenta águas bicarbonatadas cálcicas ou magnesianas com condutividades elétricas menores que 200 $\mu \mathrm{S} / \mathrm{cm}$ e $\mathrm{pH}$ inferiores a 7,5. No entanto a ocorrência de águas bicarbonatadas sódicas e sulfatadas cálcicas em determinadas porções deste aquífero indicaria a conexão hidráulica com o SAG e consequente mistura de águas.

\section{CONDUTIVIDADE ELÉTRICA (CE)}

Segundo Custódio e Llamas (1983), a 
condutividade elétrica da água consiste na capacidade de conduzir eletricidade, estando diretamente relacionada à quantidade de sais dissolvidos (STD) sob a forma de íons. A unidade padrão de medida da condutividade no SI (Sistema Internacional) é a Siemens (S) e os valores para as águas subterrâneas são referidos ao milionésimo do $\mathrm{S} / \mathrm{cm}$, ou seja, $\mu \mathrm{S} / \mathrm{cm}$, a uma temperatura padrão de $25^{\circ} \mathrm{C}$. A condutividade elétrica é diretamente proporcional ao teor de sais dissolvidos e permite obter sua estimativa de modo bastante econômico e prático.

\section{MATERIAIS E MÉTODOS}

A metodologia proposta visa a integração de dados de campo com a análise exploratória de dados, associados á análises físico-químicas e feições estruturais regionais compiladas da bibliografia. Para tanto são utilizados os métodos a seguir:

\subsection{Base de dados de poços tubulares}

Para realizar este estudo foram compilados dados existentes de poços tubulares profundos construídos pela Companhia Riograndense de Saneamento (CORSAN); pelo Programa de Açudes e Poços da Secretaria de Obras Públicas do RS (PAP/SOPS); pela Companhia Integrada de Desenvolvimento Agrícola de Santa Catarina (CIDASC) e por empresas privadas de perfuração de poços. Tais informações integram o banco de dados do SIAGAS. Os dados georreferenciados relacionados aos poços contêm, idealmente, informações sobre litologias atravessadas durante a perfuração, espessura do manto de alteração, nível estático, nível dinâmico, vazão, rebaixamento, capacidade específica e entradas de água.

Durante os diversos projetos de cadastramento de poços e estudos hidrogeológicos executados pela CPRM foram realizados em campo medidas de temperatura do ar e da água, $\mathrm{pH}$ e condutividade elétrica. As medidas de temperatura do ar e da água foram registradas com termômetros de mercúrio e termômetros digitais. $\mathrm{O} \mathrm{pH}$ foi obtido com medidores de campo Lutron-206 e Orion 1230. A condutividade elétrica foi medida com condutivímetros portáteis modelos Orion 1230 e Hanna 9033, que apresentam os valores corrigidos para $25^{\circ} \mathrm{C}$.

\subsection{Análise Estatística}

O tratamento estatístico dos parâmetros hidrogeoquímicos foi realizado através de conceitos básicos da estatística descritiva e apresentação gráfica de distribuições amostrais. Para a determinação dos valores anômalos de condutividade elétrica das águas do SASG foi adotada a técnica da Análise Exploratória de Dados (AED). Tal método foi introduzido por Tukey (1977) para analisar dados que não seguem obrigatoriamente uma distribuição normal e apresenta a vantagem de não fazer muitas exigências sobre a distribuição estatística dos dados, como ocorre com outros métodos. A AED dá ênfase à exploração original com o objetivo de simplificar a descrição dos dados e obter uma visão da sua natureza. O método avalia os dados em nível preliminar sem a necessidade de hipóteses sobre a distribuição destes, empregando cálculos e gráficos relativamente simples. Os diagramas não são sensíveis a valores extremos, como outras medidas baseadas na média e desvio padrão.

Para Andriotti (2013), a AED não é somente um método, mas sim uma filosofia ou uma abordagem robusta que consiste de um conjunto de estatísticas descritivas e principalmente de ferramentas gráficas, que visam obter o máximo de informações sobre os dados. Também auxilia na definição da sua estrutura, variáveis significativas e na determinação dos outliers (valores aberrantes) e anomalias.

Pelo método da Boxplot (Figura 3) se define o IQR - Inter Quartile Range (Desvio Inter-Quartis) como a diferença entre $o$ terceiro e o primeiro quartis. Os quartis superior e inferior definem a caixa central, que contém aproximadamente $50 \%$ dos dados. Um dos valores limites é definido como uma 
caixa estendida por 1,5 vezes o comprimento da mesma em direção ao máximo a partir do $3^{\circ}$ quartil, e ao mínimo a partir do $1^{\circ}$ quartil. Os valores que estão nos extremos destes limites são os whiskers. Valores situados fora do intervalo dos whiskers são definidos como outliers. Valores além de três vezes (para mais ou para menos) a largura da faixa, acima da superior ou abaixo da inferior, são definidos como outliers extremos, ou seja, valores não usuais para o conjunto de dados. Dois valores limítrofes valem respectivamente (1,5 x IQR) e (3,0 x IQR) em direção ao valor mínimo, da mesma forma outros dois valores são definidos como (1,5 x IQR) e (3,0 x IQR), respectivamente, na direção do valor máximo. É importante ressaltar que a vantagem desta representação é a simplificação em termos de quantidades de classes. O objetivo é separar poucas categorias que apresentem individualmente significado geoquímico específico.

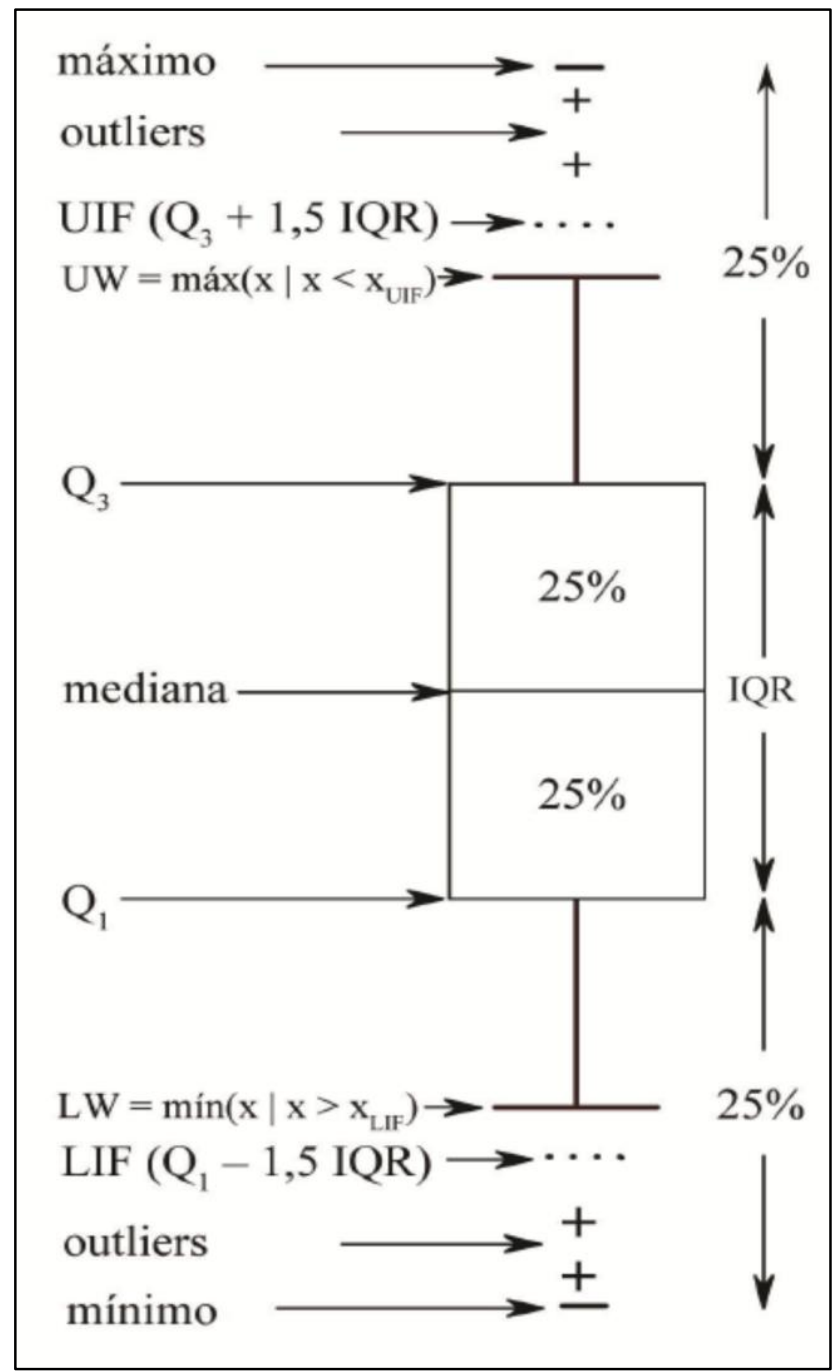

Figura 3 - Boxplot com os parâmetros utilizados na Análise Exploratória de Dados (adaptado de Andriotti, 2013)

Figure 3 - Boxplot with the parameters used in the Exploratory Data Analysis (adapted from Andriotti, 2013)

\subsection{Análise Hidroquímica}

As análises físico-químicas foram compiladas das seguintes fontes: laboratório da CORSAN, laboratório da Empresa de Pes- quisa Agropecuária e Extensão Rural de Santa Catarina (Epagri) e laboratório Quimioambiental.

Os resultados, originalmente apresentados em $\mathrm{mg} / \mathrm{L}$, foram convertidos para meq/L 
e passaram pelo cálculo da diferença de balanço iônico (DBI) conforme a equação abaixo:

$\operatorname{DBI}(\%)=100 \times\left[\left(\sum\right.\right.$ cátions $-\sum$ ânions $/$

( $\sum$ cátions $+\sum$ ânions $\left.)\right]$
Adotou-se aceitar os resultados com DBI variando $10 \%$ para mais ou para menos, conforme critério sugerido por Feitosa et al. (2008). Do total de 1.495 análises compiladas, 356 referentes ao SASG atenderam a este critério (Figura 4).

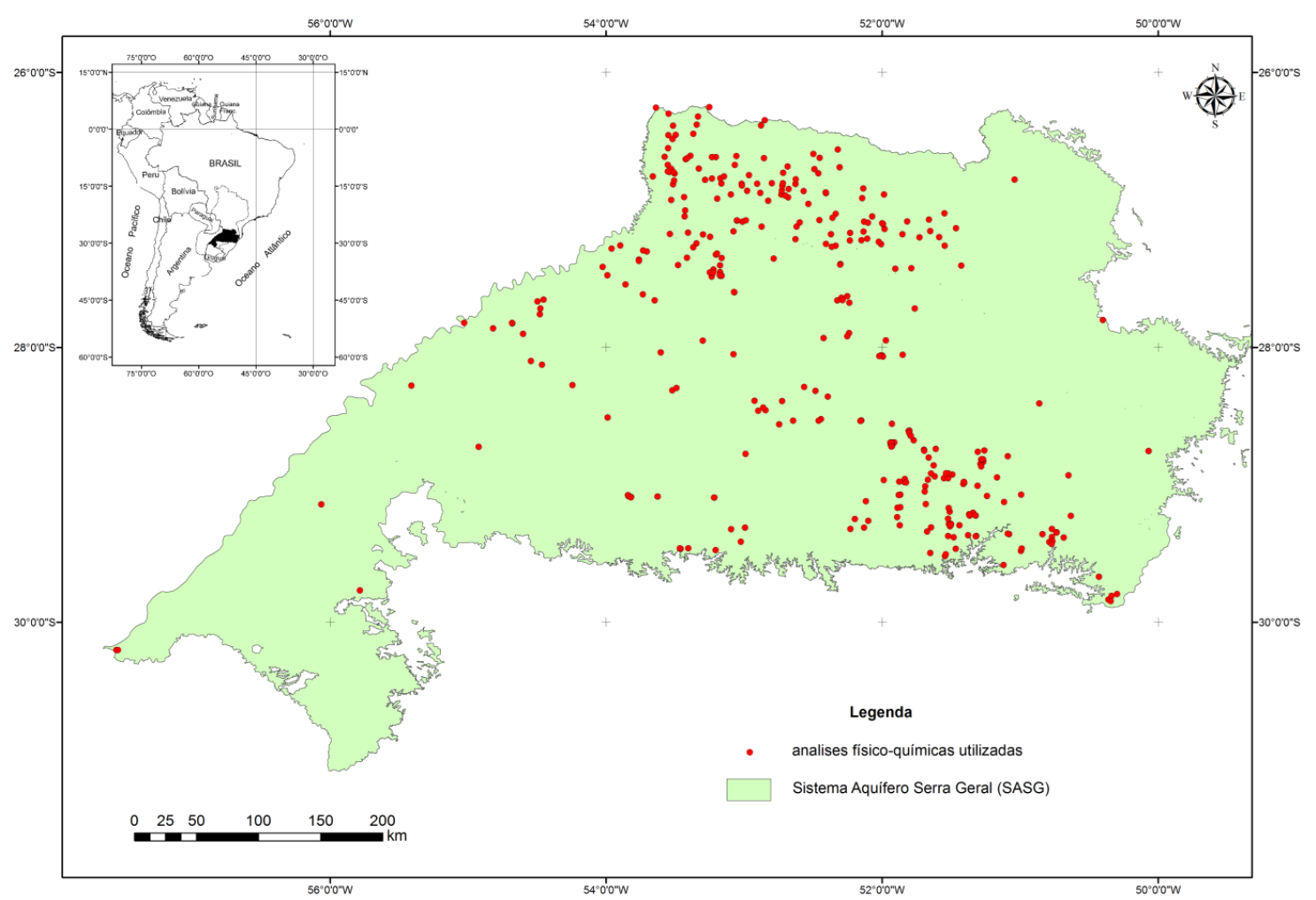

Figura 4 - Distribuição das análises físico-químicas do SASG

Figure 4 - Distribution of the SGAS physical-chemical analyses

A avaliação hidroquímica das várias classes determinadas pela AED foi realizada através da utilização do pacote computacional AquaChem versão 2011 1.61, com os tipos geoquímicos das águas determinados através do gráfico de Piper (1944), plotando-se os percentuais de miliequivalentes dos principais cátions e ânions.

\subsection{Traçado de Lineamentos Morfoes- truturais}

Os lineamentos morfoestruturais foram traçados em escala 1:1.000.000 a partir da fusão entre imagem LandSat e relevo sombreado em modelo digital do terreno, construído a partir de dados altimétricos levantados por interferometria de radar pela missão espacial Shuttle Radar Topography
Mission (SRTM-/NASA-NGA), originalmente levantados com pixels de $90 \mathrm{~m}$.

\section{RESULTADOS E DISCUSSÃO}

\subsection{Classes de Condutividade Elétrica no SASG}

A análise estatística de CE em 7.620 poços que captam água do SASG na área de estudo é apresentada no Tabela 1 . O menor valor medido, $10,31 \mu \mathrm{S} / \mathrm{cm}$, refere-se a um poço na Linha Guaritinha em Palmeira das Missões, RS, com $\mathrm{pH}$ de 5,5. O maior valor encontrado $(7.310 \mu \mathrm{S} / \mathrm{cm})$ corresponde a um poço situado na localidade de Santo Antonio do Meio em União do Oeste, SC. A distribuição dos valores de condutividade elétrica segue uma distribuição log-normal, 
conforme pode ser observado na Figura 5.

Como o valor encontrado através da AED na classe inferior é negativo, assume-se o menor valor medido, ou seja, $10,21 \mu \mathrm{S} / \mathrm{cm}$.

As classes encontradas para o conjunto de dados estão relacionadas no Tabela 2.

Tabela 1 - Análise estatística descritiva da CE nos poços que captam água do SASG

Table 1 - Descriptive statistics of the EC in the wells that capture water from SGAS

$\begin{array}{lc}\mathrm{N}^{\circ} \text { de Medidas } & 7.620 \\ \text { Mínima } & 10,21 \\ \text { Máxima } & 7.310,00 \\ \text { Média } & 192,56 \\ \text { Mediana } & 167,00 \\ \text { Moda } & 202,00 \\ \text { Desvio padrão } & 169,99 \\ \text { Quartil inferior }\left(\mathrm{Q}_{1}\right) & 117,35 \\ \text { Quartil superior }\left(\mathrm{Q}_{3}\right) & 221,75 \\ \text { Distância entre quartis }(\mathrm{IQR}) & 104,40 \\ \text { Coeficiente de Variação } & 88,28\end{array}$

Tabela 2 - Classes de valores de CE a partir da Análise Exploratória de Dados nos poços que captam água do SASG

Table 2 - EC values classes from the Exploratory Data Analysis in the wells that capture water from SGAS

\begin{tabular}{|c|c|c|c|c|}
\hline & \multirow{2}{*}{ Classes } & \multicolumn{3}{|c|}{$\mathrm{CE}(\mu \mathrm{S} / \mathrm{cm})$} \\
\hline & & intervalo & $\mathrm{n}^{\mathrm{o}}$ poços & $(\%)$ \\
\hline $\mathrm{C} 1$ & $\geq \mathrm{Q}_{3}+1,5(\mathrm{IQR})$ & $\geq 378,35$ & 361 & 4,73 \\
\hline $\mathrm{C} 2$ & $\mathrm{Q}_{3} \mathrm{a} \mathrm{Q}_{3}+1,5(\mathrm{IQR})$ & 221,75 a 378,35 & 1.544 & 20,27 \\
\hline $\mathrm{C} 3$ & $\mathrm{Q}_{1}$ a $\mathrm{Q}_{3}$ & 117,35 a 221,75 & 3.810 & 50,00 \\
\hline $\mathrm{C} 4$ & $\mathrm{Q}_{1}-1,5(\mathrm{IQR})$ a $\mathrm{Q}_{1}$ & 10,21 a 117,35 & 1.905 & 25,00 \\
\hline
\end{tabular}

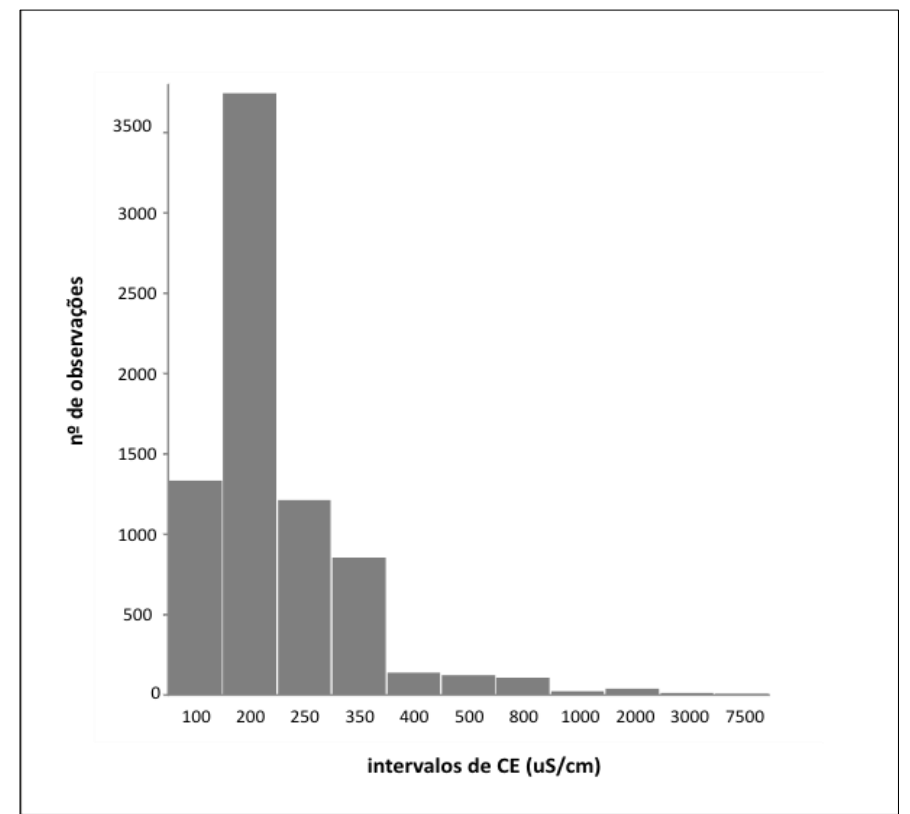

Figura 5 - Histograma da CE medida in loco em 7.620 poços tubulares que captam água do SASG

Figure 5 - Histogram of the EC in 7.620 tubular in 7.620 tubular wells that capture water in the SGAS

Os valores de CE concentram-se na faixa de background, entre 117,35 e 378,35 $\mu \mathrm{S} / \mathrm{cm}$. Valores acima e abaixo destes limites são considerados anômalos. A Figura 6 ilustra a distribuição espacial dos poços separados conforme as classes de CE do SASG obtidas através da AED. 


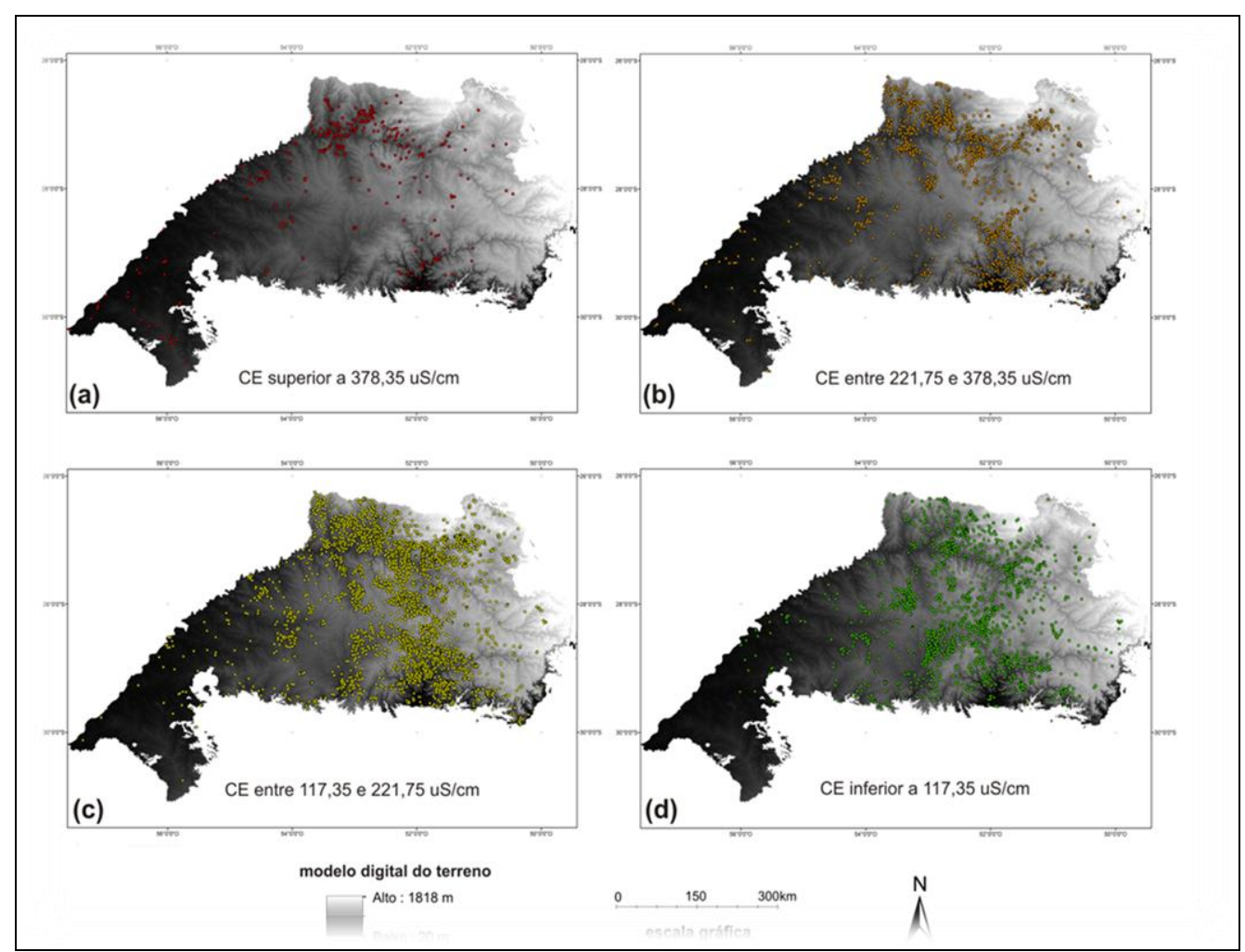

Figura 6 - Poços tubulares separados conforme as classes de CE determinadas na AED sobre modelo digital do terreno. Classes C1 (a); C2 (b); C3 (c) e C4 (d)

Figure 6 - Water wells separated according to the EC classes identified in the EDA on the digital terrain model. Classes C1 (a); C2 (b); C3 (c) e C4 (d)

A classe $\mathrm{C} 1$ contém 37 análises físicoquímicas; a classe C2, 93; a classe C3, 180 e a classe C4, 46 análises. O Tabela 3 apresenta os valores mínimos, máximos, médias e medianas dos principais parâmetros físicoquímicos das análises de poços separa-dos pelas classes AED.

A tipologia geoquímica das águas a partir da plotagem dos resultados nos diagramas de Piper das diversas classes AED de CE revelou na classe $\mathrm{C} 1$ (Figura7-a) águas predominantemente sulfatadas/cloretadas sódicas e bicarbonatadas sódicas. Também ocorrem em menor número águas bicarbonatadas cálcicas/magnesianas e sulfatadas/ cloretadas-cálcicas/magnesianas. As águas da classe $\mathrm{C} 1$ têm em geral caráter alcalino e altos teores de sódio, sulfato, cloretos e fluoretos.

A Classe C2 (Figura 7 - b) apresenta duas tipologias hidrogeoquímicasn bem definidas: águas bicarbonatadas cálcicas/ magnesianas $(65,6 \%)$ e bicarbonatadas sódicas $(34,4 \%)$. São águas menos salinas que as da classe $\mathrm{C} 1$, levemente alcalinas, com maior teor de cálcio, baixo sulfato, maior dureza e baixos teores de flúor. $\mathrm{O}$ primeiro tipo tem suas características físico-químicas coerentes com águas de recarga por manto de alteração como verificado por Lisboa (1996), Freitas et al. (2002) e Reginato e Strieder (2006). O tipo de águas bicarbonatadas sódicas pode estar relacionado com águas de maior tempo de residência no aquífero, que sofreram uma evolução geoquímica natural, conforme mencionado por Lisboa (1996), Machado e Freitas (2000) ou a mistura com águas do SAG (Freitas et al., 2002).

De características semelhantes à $\mathrm{C} 2$, a classe C3 (Figura 7-c), tem uma maior predominância do tipo hidrogeoquímico de águas bicarbonatadas cálcicas/magnesianas $(78,3 \%)$. As águas bicarbonatadas sódicas estão presentes no restante dos casos. Esta classe apresenta águas com menor teor de sais dissolvidos, neutras a levemente alcalinas, predomínio de cálcio e magnésio, baixos teores de flúor e sulfatos. 
Na classe C4 (Figura 7-d) ocorrem com maior frequência as águas do tipo bicarbonatadas cálcicas/magnesianas $(82,6 \%)$, enquanto que as águas bicarbonatadas sódicas representam somente $17,4 \%$ dos casos. São águas com baixo teor de sais dissolvidos, caráter neutro a levemente ácido e baixos teores de flúor. Na maior parte dos casos, estas águas ocorrem em regiões planas, mais elevadas, com relevos menos dissecados e maiores espessuras de manto de alteração, indicando boas condições de recarga por precipitação pluviométrica.

Tabela 3 - Análise estatística dos principais parâmetros físico-químicos das águas do SASG conforme as classes de CE identificadas pela Análise Exploratória de Dados

Table 3 - Statistical anlysis of the main physical-chemical parameters of water of SGAS according to EC classes identified by EDA

\begin{tabular}{|c|c|c|c|c|c|}
\hline \multicolumn{2}{|c|}{ Classes de AED } & \multirow{2}{*}{$\begin{array}{l}\text { C1 } \\
37\end{array}$} & \multirow{2}{*}{$\begin{array}{l}\text { C2 } \\
93\end{array}$} & \multirow{2}{*}{$\begin{array}{c}\mathrm{C3} \\
180\end{array}$} & \multirow{2}{*}{$\begin{array}{l}\mathrm{C} 4 \\
46\end{array}$} \\
\hline Número de poços & & & & & \\
\hline Variáveis & Estatística & & & & \\
\hline \multirow{3}{*}{$\mathrm{STD}(\mathrm{mg} / \mathrm{L})$} & mínimo & 149,00 & 125,00 & 71,60 & 31,00 \\
\hline & máximo & $4.519,00$ & 312,00 & 450,00 & 326,00 \\
\hline & mediana & 377,50 & 189,00 & 142,30 & 100,15 \\
\hline \multirow{3}{*}{$\mathrm{pH}$} & mínimo & 6,69 & 6,00 & 6,38 & 5,67 \\
\hline & máximo & 10,90 & 10,08 & 10,00 & 9,72 \\
\hline & mediana & 8,56 & 7,76 & 7,40 & 6,70 \\
\hline \multirow{3}{*}{$\begin{array}{c}\mathrm{Na}^{+}+\mathrm{K}^{+} \\
(\mathrm{mg} / \mathrm{L})\end{array}$} & mínimo & 6,10 & 0,50 & 3,00 & 2,20 \\
\hline & máximo & 725,00 & 81,20 & 107,00 & 65,66 \\
\hline & mediana & 115,54 & 20,40 & 14,22 & 9,20 \\
\hline \multirow{3}{*}{$\begin{array}{c}\mathrm{Ca}^{2+} \\
(\mathrm{mg} / \mathrm{L})\end{array}$} & mínimo & 0,80 & 1,20 & 0,30 & 2,40 \\
\hline & máximo & 561,12 & 47,00 & 38,00 & 30,00 \\
\hline & mediana & 5,61 & 23,00 & 16,60 & 10,00 \\
\hline \multirow{3}{*}{$\begin{array}{l}\mathrm{Mg}^{2+} \\
(\mathrm{mg} / \mathrm{L})\end{array}$} & mínimo & 0,10 & 0,12 & 0,10 & 0,40 \\
\hline & máximo & 44,00 & 17,50 & 29,00 & 12,00 \\
\hline & mediana & 2,43 & 5,30 & 4,85 & 3,15 \\
\hline \multirow{3}{*}{$\begin{array}{c}\mathrm{HCO}_{3}^{-}+\mathrm{CO}_{3}{ }^{2-} \\
(\mathrm{mg} / \mathrm{L})\end{array}$} & mínimo & 23,95 & 25,60 & 34,00 & 12,00 \\
\hline & máximo & 432,00 & 240,00 & 173,00 & 139,80 \\
\hline & mediana & 146,00 & 136,33 & 100,00 & 58,55 \\
\hline \multirow{3}{*}{$\begin{array}{c}\mathrm{Cl}^{-} \\
(\mathrm{mg} / \mathrm{L})\end{array}$} & mínimo & 2,00 & 0,05 & 0,20 & 1,00 \\
\hline & máximo & $1.885,94$ & 90,00 & 113,00 & 24,00 \\
\hline & mediana & 76,00 & 8,45 & 5,00 & 3,00 \\
\hline \multirow{3}{*}{$\begin{array}{l}\mathrm{SO}_{4}{ }^{2-} \\
(\mathrm{mg} / \mathrm{L})\end{array}$} & mínimo & 0,70 & 0,00 & 0,00 & 0,00 \\
\hline & máximo & $1.137,50$ & 71,40 & 94,00 & 88,70 \\
\hline & mediana & 50,00 & 3,20 & 1,20 & 1,15 \\
\hline \multirow{3}{*}{$\begin{array}{c}\mathrm{F}^{-} \\
(\mathrm{mg} / \mathrm{L})\end{array}$} & mínimo & 0,01 & 0,02 & 0,02 & 0,03 \\
\hline & máximo & 3,60 & 2,80 & 10,60 & 0,60 \\
\hline & mediana & 1,30 & 0,30 & 0,20 & 0,20 \\
\hline \multirow{3}{*}{$\begin{array}{l}\text { Dureza Total } \\
\left(\mathrm{mg} / \mathrm{L} \mathrm{CaCO}_{3}\right)\end{array}$} & mínimo & 3,00 & 3,40 & 4,00 & 8,00 \\
\hline & máximo & $1.380,00$ & 171,00 & 124,00 & 103,00 \\
\hline & mediana & 24,00 & 87,50 & 61,50 & 35,00 \\
\hline
\end{tabular}




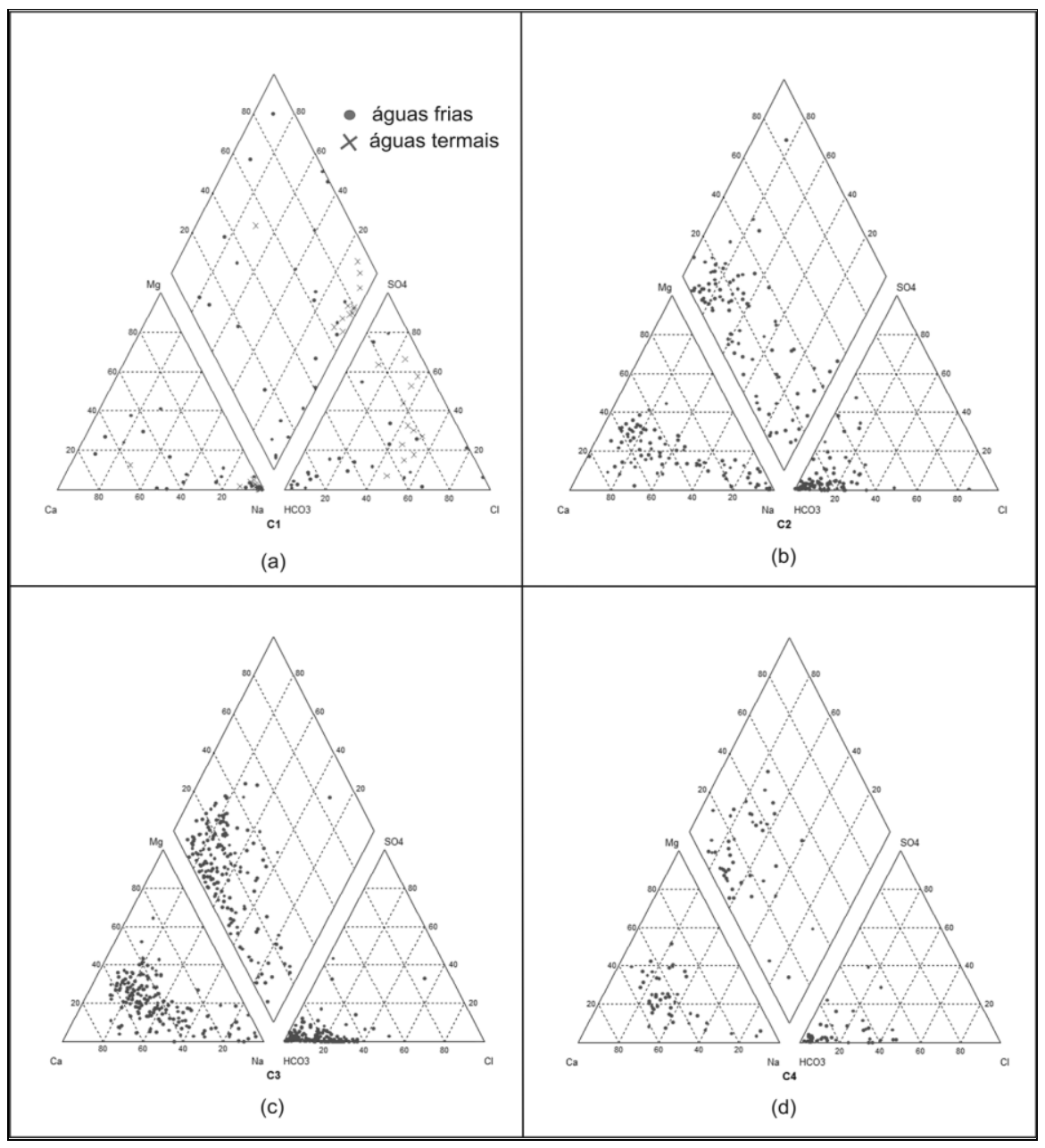

Figura 7 - Diagramas de Piper das classes de CE identificadas pela AED no SASG: C1 (a); C2 (b); C3 (c) e $\mathrm{C} 4$ (d). Nota-se a presença de águas termais na classe $\mathrm{C} 1$ e a evolução geoquímica das águas de $\mathrm{C} 4$ para $\mathrm{C} 1$

Figure 7 - Piper Diagrams of EDA classes of EC in SGAS: C1 (a); C2 (b); C3 (c) and C4 (d). Note the presence of thermal waters in the class $\mathrm{C} 1$ and the water geochemical evolution from $\mathrm{C} 4$ to $\mathrm{C} 1$.

\subsection{Zonas de CE Anômala}

Os poços no SASG referentes à classe $\mathrm{C} 1$ geralmente ocupam as áreas mais dissecadas e rebaixadas topograficamente, coincidentes com os vales alinhados dos principais rios da região. A Figura 8 apresenta poços com valores anômalos de CE no SASG em conjunto com as principais feições estruturais regionais da área de estudo compiladas de diversos autores (Asmus, 1975; Soares et al., 1982; Zalán et al., 1986; Machado, 2005; Soares et al., 2008; Giardin e Faccini, 2010; Philipp et al., 2014); e outras traçadas em imagens de satélite e modelo digital do terreno, propostas neste trabalho.

A evidente concentração espacial destes poços, alinhados com as principais zo- nas de falhas e lineamentos, leva à proposição das seguintes zonas anômalas em relação a CE no SASG do Rio Grande do Sul e Santa Catarina: Zona Alto Uruguai/ Extremo Oeste; Zona Alto Uruguai/Meio Oeste; Zona Taquari/Antas; Zona Missões/ Noroeste e Zona Fronteira Oeste.

Algumas pequenas concentrações esparsas de poços anômalos ocorrem na área de estudo e devem, provavelmente, estar relacionadas com águas de maior tempo de residência no aquífero ou mesmo à presença de estruturas menores, que não são mapeáveis neste trabalho de escala regional.

\subsubsection{Zona Alto Uruguai/Extremo Oeste}

Esta zona (Figura 8) localiza-se na re- 
gião do extremo oeste de Santa Catarina e norte/noroeste do Rio Grande do Sul. Seu controle estrutural está intimamente relacionado com a presença da zona de falha Lancinha-Cubatão (Zalán et al., 1990), de direção $\mathrm{N} 60^{\circ} \mathrm{E}$, do lineamento do Rio Chapecó $\left(\mathrm{N} 55^{\circ} \mathrm{E}\right)$ e do lineamento do Rio Uruguai (Asmus,1975), com orientação praticamente E-W. Os poços anômalos estão orientados nessas direções, onde estão encaixados os vales dos rios Chapecó e Uruguai. Secundariamente ocorre uma série de anomalias orientadas a $\mathrm{N} 10^{\circ} \mathrm{W}$ ao longo do Rio das Antas, em Santa Catarina e do Rio da
Várzea, na região de Frederico Westphalen e Ametista do Sul, no Rio Grande do Sul. Tratase da área de maior confinamento do SAG nesses dois Estados, com espessuras de rochas vulcânicas entre 1.100 e 1.400 metros. As águas desta zona apresentam as maiores condutividades elétricas da área de estudo. Também consiste na única zona de anomalia onde ocorrem águas termais no SASG, que são aproveitadas em diversos balneários da região como em Iraí e Vicente Dutra, no Rio Grande do Sul, e Palmitos, Águas de Chapecó, São Carlos, Barra Bonita e Quilombo, em Santa Catarina (FREITAS et al., 2011).

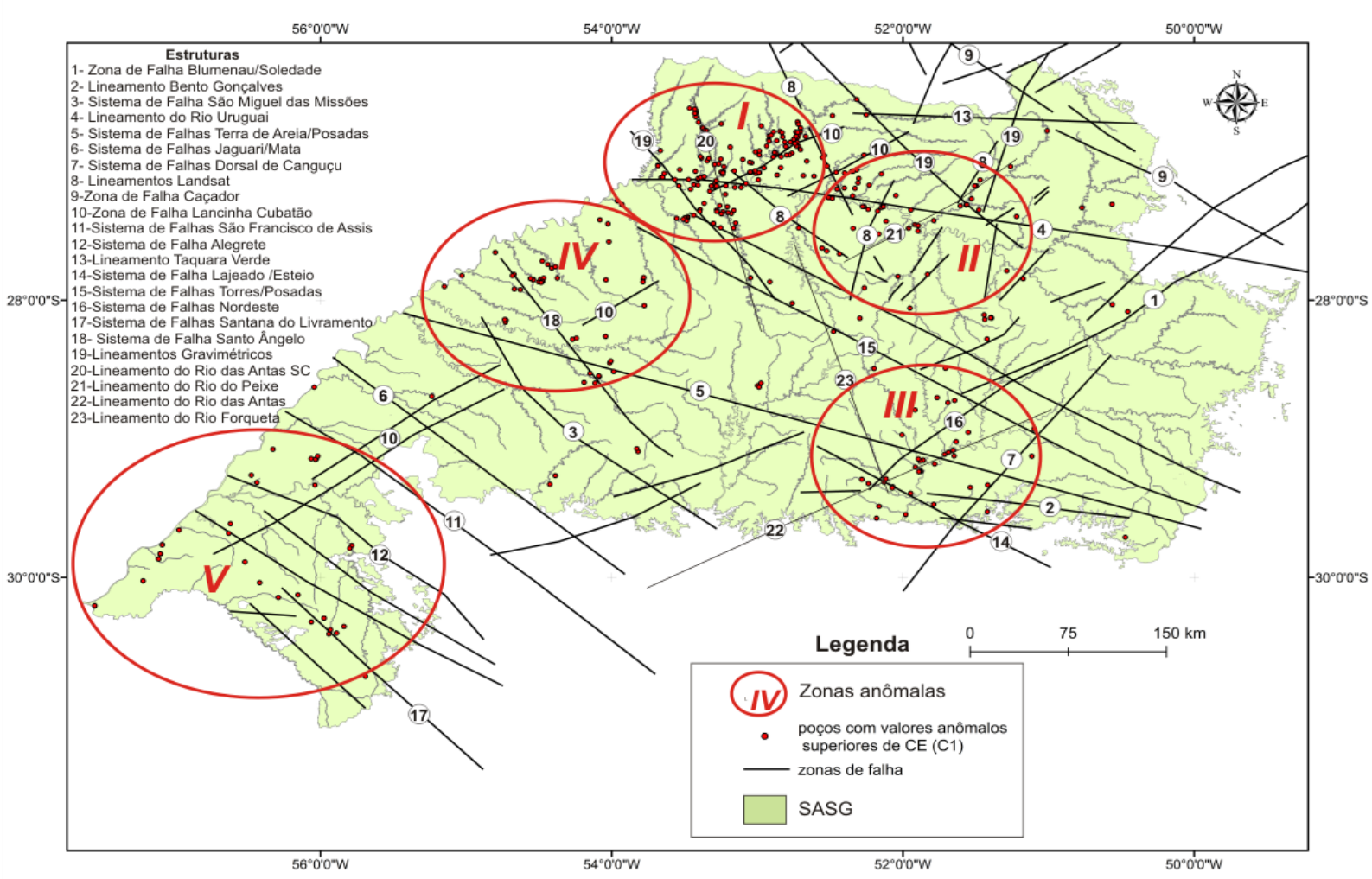

Figura 8 - Zonas de CE anômalas e as principais feições tectônicas da área de estudo traçadas a partir de fontes de diferentes autores: Asmus (1975); Soares et al. (1982); Zalán et al. (1990); Machado (2005); Soares et al.(2008); Giardin e Faccini (2010); Philipp et al. (2014)

Figure 8 - Anomalous EC zones and main tectonic structures of the study area by different authors: Asmus (1975); Soares et al. (1982); Zalán et al. (1990); Machado (2005); Soares et al. (2008); Giardin and Faccini (2010); Philipp et al. (2014)

\subsubsection{Zona Alto Uruguai/Meio Oeste}

Esta zona abrange o meio oeste catarinense e parte do norte do Rio Grande do Sul, sendo delimitada pelos rios Irani e do Peixe (Figura 8). Seu relevo apresenta um intenso grau de dissecação, encostas com alta declividade e muitos cursos d'água orientados por lineamentos morfoestruturais.

Os poços que captam as águas anômalas no SASG estão alinhados segundo o lineamento do Rio Uruguai (Asmus, 1975); a zona de falha Lancinha-Cubatão (Zalán et al., 1990); os lineamentos gravimétricos e traça- 
dos em imagens de satélite de direção $\mathrm{N} 25^{\circ} \mathrm{W}$ e $\mathrm{N} 50^{\circ} \mathrm{W}$ (Soares et al., 1982); bem como no lineamento do Rio do Peixe, de direção $\mathrm{N} 60^{\circ} \mathrm{E}$, proposto no presente trabalho. A espessura do SASG varia de leste para oeste entre 400 e 1.000 metros, respectivamente e a $\mathrm{CE}$ das águas atinge valor máximo de 1.233 $\mu \mathrm{S} / \mathrm{cm}$, enquanto o $\mathrm{pH}$ varia entre $6,15 \mathrm{e}$ 11,00 , com média de 8,29 e mediana de 7,95.

\subsubsection{Zona Taquari/Antas}

A Zona Taquari/Antas (Figura 8) ocorre na porção centro sul da área de estudo junto ao vale do Rio Taquari no Rio Grande do Sul, onde as espessuras do SASG variam de 45 a 800 metros. O relevo é bastante dissecado e tem íntima associação com as estruturas tectônicas presentes na área. $\mathrm{O}$ controle estrutural dos poços anômalos está associado às seguintes feições: lineamento do Rio das Antas (Giardin e Faccini, 2010), de direção $\mathrm{N} 70^{\circ} \mathrm{E}$; sistema de falhas LajeadoEsteio, com direção $\mathrm{N} 60^{\circ} \mathrm{W}$; zona de falha Blumenau-Soledade $\left(\mathrm{N} 65^{\circ} \mathrm{E}\right)$; sistema de falha Dorsal de Canguçu $\left(\mathrm{N} 40^{\circ} \mathrm{E}\right)$; sistema de falha nordeste e lineamento Bento Gonçalves (E-W), de acordo com Philipp et al. (2014). Os poços anômalos pertencentes a essa zona apresentam CE entre 379 e $1.325 \mu \mathrm{S} / \mathrm{cm}$, com média de $518,87 \mu \mathrm{S} / \mathrm{cm}$ e mediana de 438 $\mu \mathrm{S} / \mathrm{cm}$. O pH varia de 6,69 a 9,10, com média e mediana respectivas de 7,72 e 7,60.

\subsubsection{Zona Missões/Noroeste}

Abrangendo a região noroeste do Rio Grande do Sul ocorre a Zona Missões/Noroeste, cuja espessura do SASG varia entre 300 e 1200 metros. A região (Figura 8) apresenta um relevo menos dissecado e presença de manto de alteração mais espesso. Esta zona está condicionada pelos sistemas de falha Terra de AreiaPosadas (Machado, 2005), de direção N75 $\mathrm{W}$; Santo Ângelo (Philipp et al., 2014), com direção $\mathrm{N} 35^{\circ} \mathrm{W}$; e Lancinha-Cubatão (Zalán et al., 1990). Os poços com anomalia de CE no SASG atingem valores máximos de 718 $\mu \mathrm{S} / \mathrm{cm}$. O pH das águas varia de 6,60 a 10,50, com média de 6,53 e mediana de 9,30. Esta zona contém as águas mais alcalinas das zonas anômalas.

\subsubsection{Zona Fronteira Oeste}

Esta zona ocorre na região oeste do Estado do Rio Grande do Sul (Figura 8), cujo relevo é bastante arrasado e plano, encontrando-se muito próxima da principal área de afloramento e recarga do SAG no Estado. As espessuras do SASG estão entre 100 e 500 metros e o controle estrutural está relacionado com a zona de falha LancinhaCubatão, de direção NE; e com as estruturas, de orientação N-W, sistema de falha JaguariMata (Machado, 2005), bem como com os sistemas de falha São Francisco de Assis, Alegrete e Santana do Livramento, descritas por Philipp et al. (2014). Os poços existentes que captam exclusivamente o SASG atingem a profundidade máxima de $265 \mathrm{~m}$ e os valores de CE oscilam entre 385 e $900 \mu \mathrm{S} / \mathrm{cm}$, com média e mediana de 501,48 e $443 \mu \mathrm{S} / \mathrm{cm}$, respectivamente. $\mathrm{O} \mathrm{pH}$ varia de 6,2 a $8,5 \mathrm{com}$ média de 7,57 e mediana 7,5.

\section{CONCLUSÕES}

A metodologia de integração de dados de campo com a análise exploratória de dados, associados a análises físico-químicas e feições estruturais regionais mostrou ser eficiente e pode ser aplicada para outras regiões onde ocorre o SASG.

As águas do SASG apresentam um background de condutividade elétrica entre 117,35 e $378,35 \mu \mathrm{S} / \mathrm{cm}$. As anomalias correspondem a valores superiores e inferiores a estes limites.

As classes de CE obtidas na AED refletiram uma evidente separação baseada na evolução geoquímica das águas do SASG, onde a classe $\mathrm{C} 1$ está ligada às águas mais antigas e muitas vezes misturadas com águas dos aquíferos sotopostos, apresentando íntima relação com as estruturas regionais como zonas de falhas e lineamentos. Localmente há mistura através de recarga ascendente no SASG com águas dos aquíferos sotopostos 
através das estruturas, em locais onde a carga hidráulica é favorável. As classes C2 e C3 abrigam as águas típicas do SASG e sua variação deve-se, prova-velmente, ao tempo de residência no aqui-fero. A classe $\mathrm{C} 4$ referese às águas mais jovens que se infiltraram recentemente no aquífero pela recarga meteórica através do manto de alteração das rochas vulcânicas.

O controle estrutural das águas possibilitou a separação de cinco grandes zonas com características hidroquímicas distintas e anômalas.

Os poços da zona Alto Uruguai/ Extremo Oeste são os que têm maior salinidade em suas águas e os únicos que apresentam termalismo, com temperaturas de até $38^{\circ} \mathrm{C}$. Nesta zona a espessura do SASG é a maior dentre todas as outras, atingindo valores superiores a 1.400 metros, sendo o controle estrutural predominante NE e NW. As águas termais no SASG estão controladas pelo lineamento do Rio Uruguai, zona de falha

\section{REFERÊNCIAS}

ANDRIOTTI, J. L. S. Aplicação da EDA Exploratory Data Analysis - na determinação de parâmetros em prospecção geoquímica. In: CONGRESSO BRASILEIRO DE GEOQUIMICA, 14.; SIMPOSIO LATINO-AMERICANO DE MAPEAMENTO GEOQUIMICO, 2013, Diamantina, MG. Anais.... Diamantina, MG: SBGq, 2013. 1 CDROM.

ARAÚJO, L.M; FRANÇA, A.B; POTTER, P.E. Aquífero gigante do Mercosul no Brasil, Argentina, Uruguai e Paraguai: mapas hidrogeológicos das formações Botucatu, Piramboia, Rosario do sul, Buena Vista Misiones e Tacuarembo. Curitiba: UFPRPetrobras, 1995. 15 p. il.;8 mapas.

ASMUS, H. E. Controle estrutural da deposição mesozóica nas bacias da margem continental brasileira. Revista Brasileira de Geociências, São Paulo, v. 5, n. 3, p. 160-175, 1975.

BETIOLLO, L. M. Caracterização estrutural, hidrogeológica e hidrogeoquímicas dos sistemas Sistema Aquíferos Guarani e Serra Geral no nordeste do Rio grande do Sul, Brasil. 2006. 117 f. Dissertação (Mestrado) - Instituto de Geociências, Programa de Pós-Graduação em Geociências, Univer-
Lancinha-Cubatão e lineamento do Rio Chapecó.

A zona Alto Uruguai/Meio Oeste é muito semelhante à anteriormente citada, mas sua salinidade e espessura são menores e não há poços termais no SASG. O controle estrutural principal está ligado às direções NW, NE e EW.

$\mathrm{Na}$ zona Taquari/Antas as espessuras de rochas vulcânicas são menores e as águas apresentam salinidade inferior e caráter neutro a levemente alcalino. Esta zona tem controle principal relacionado às direções NE e NW de alto ângulo.

A zona Missões/Noroeste apresenta os poços mais profundos e mais alcalinos da área de estudo e seu controle estrutural é essencialmente NW.

$\mathrm{Na}$ zona Fronteira Oeste, onde o controle estrutural está vinculado com falhas de direção NW, as espessuras do SASG são geralmente pequenas, estando o sistema aquífero muito próximo da área de afloramento e recarga direta do SAG.

sidade Federal do Rio Grande do Sul, Porto Alegre, 2006.

CUSTODIO, E.; LLAMAS, M. R. Hidrologia

Subterránea. 2.ed. Barcelona: Omega, 1983. 2 v.

FRAGA, G. C. Introdução ao zoneamento do Sistema Aquífero Serra Geral no estado do Paraná. 1986. 132 f. Dissertação (Mestrado) - Instituto de Geociências, Universidade de São Paulo, 1986.

FEITOSA, F. A. C.; MANOEL FILHO, J.; FEITOSA, E. C.; DEMÉTRIO, J. G. A. (Coord.)

Hidrogeologia: conceitos e aplicações. 3.ed.

Fortaleza: CPRM/LABHID, 2008. 812 p.

FREITAS, M. A.; MACHADO, J. L. F.

Hidrogeoquímica do Sistema Aquífero Serra Geral no Oeste de Santa Catarina. In: CONGRESSO

MUNDIAL INTEGRADO DE AGUAS

SUBTERRANEAS, 1., ; JOINT WORLD

CONGRESS ON GROUNDWATER, 2000, Fortaleza.

Resumos... Fortaleza: ABAS/ALHSUD, 2000.

FREITAS, M. A. de; CAYE, B. R.; MACHADO, J. L. F. Diagnóstico dos recursos hídricos subterrâneos do oeste do estado de Santa Catarina. Porto Alegre: CPRM/SDM-SC/SDA-SC/EPAGRI. 2002.100 p.

(Projeto Oeste de Santa Catarina) 
FREITAS, M. A.; ROISENBERG, A.; CUNHA, G.G. Caracterização hidrogeoquímica preliminar das fontes termais da região do Alto Rio Uruguai-RS e SC. In: CONGRESSO BRASILEIRO DE GEOQUIMICA,13.; SIMPOSIO DE GEOQUIMICA DOS PAISES DO MERCOSUL, 3, 9-14 out. 2011, Gramado. Anais... Gramado: UFRGS/CEPG, 2011. Disponível em:

$<$ http://sbgq.org.br/index.php?option=com phocadow nloadeview $=$ fileeid $=493$ eItemid $=180>$. Acesso em: 22 maio 2015.

FREITAS, M. A.; BINOTTO, R. B.; NANNI, A.S.; RODRIGUES, A. L. M.; BORTOLI, C. R. Avaliação do potencial hidrogeológico, vulnerabilidade intrínseca e hidroquímica do Sistema Sistema Aquífero Serra Geral no noroeste do estado do Rio Grande do Sul. 2012. Revista Brasileira de Recursos Hídricos, RBRH, Porto Alegre, RS, v. 17, n. 2, p. 31 41, 2012.

GIARDIN, A.; FACCINI, U. Termalismo e hidroquímica como evidências de limite de fluxo regional no Sistema Aquífero Guarani no Sul do Brasil. Revista Águas Subterrâneas, ABAS, São Paulo, v. 24, n.4, p.1-12, 2010.

HAUSMAN, A. Províncias hidrogeológicas do estado do Rio Grande do Sul, RS. São Leopoldo, RS: Unisinos , 1995. 127 p. 1 mapa. Escala 1:50.000, 1995. (Acta Geológica Leopoldensia, Série Mapas, v. 2).

LISBOA, N. A. Fácies, estratificação

hidrogeoquímica e seus controladores geológicos em unidades geológicas do Sistema Aquífero Serra Geral na Bacia do Paraná, Rio Grande do Sul. 1996. 135 f. Tese (Doutorado)-. Curso de PósGraduação em Geociências, Universidade Federal do Rio Grande do Sul, Porto Alegre, 1986.

MACHADO, J. L. F. Compartimentação espacial e arcabouço hidroestratigráfico do sistema aquífero Guarani no Rio Grande do Sul. 2005. 225 f. Tese (Doutorado em Geologia Sedimentar)-Centro Tecnológico, Universidade do Vale do Rio dos Sinos, São Leopoldo, 2005.

MACHADO, J. L. F.; FREITAS, M. A. de. Hidroquímica do Sistema Aquífero Serra Geral no Oeste de Santa Catarina. In: CONGRESSO

MUNDIAL INTEGRADO DE AGUAS

SUBTERRANEAS, 1. JOINT WORLD CONGRESS ON GROUNDWATER, 2000, Fortaleza. Resumos... Fortaleza: ABAS/ALHSUD, 2000.

MACHADO, R. ; ROLDAN, L. F.; JACQUES, P. D.; FASSBINDER, E.; NUMMER, A. R. Tectônica Transcorrente mesozoica-cenozoica no Domo de Lages - Santa Catarina. Revista Brasileira de
Geociências, São Paulo, v. 4, p. 799, 2012.

NANNI, A. S. O flúor em águas do Sistema Aquífero Serra Geral no Rio Grande do Sul: origem e condicionamento geológico. 2008. 145 f. Tese (Doutorado) - Curso de Pós-Graduação em Geociências Universidade Federal do Rio Grande do Sul, Porto Alegre, 2008.

PHILIPP, R.P.; ROLIM, S.B.A.; MALTA, L.; JELINEK, A.R.; VIANA, A.; LAVINA,

E.;CAGLIARI, J.; FACCINI, U.F. Estruturação do Arco de Rio Grande e da Sinclinal de Torres, Bacia do Paraná, RS: Evidências por levantamentos magnetotelúricos. In: SIMPOSIO SUL-BRASILEIRO DE GEOFISICA, 6, out. 2014, Porto Alegre.

Resumos Expandidos.... Porto Alegre: SBGf, 2014. 1 CD ROM.

PIPER, A. M. A graphic procedure in the geochemical interpretation of water analyses. Trans. Amer.

Geophysical Union, v. 25, p.914-928, 1944.

REBOUÇAS, A.C.; FRAGA, C. G. Hidrogeologia das rochas vulcânicas do Brasil. Revista Águas

Subterrâneas, São Paulo, n.12, p.30-55, 1988.

REGINATO, P. A. R.; STRIEDER , A. Integração de dados geológicos na prospecção de aquíferos fraturados na Formação Serra Geral. Revista Águas Subterrâneas, São Paulo v. 20, n. 1, p.1-14, 2006.

REGINATO, P.A.R.; AHLERT, S.;SCHNEIDER, V.E. Caracterização Hidroquímica do Sistema Aquífero Serra Geral na região nordeste do Rio Grande do Sul. Revista Águas Subterrâneas, v. 27, n. 1, p.65-78, 2013. Disponível em: <

http://aguassubterraneas.abas.org/asubterraneas/article /view/27061>. Acesso em:15 maio 2015.

SOARES, P.C.; BARCELOS, P.E.; CSORDAS, S.M. Análise, interpretação e integração de lineamentos a partir de imagens (radar-Landsat) e suas relações com a tectônica da Bacia do Paraná. São Paulo: Relatório RT-342/82-PAULIPETRO- Consórcio CESP/IPT, 1982.

SOARES, A. P. ; SOARES, P. C. ; BETTU, D. F. ; HOLZ, M. Compartimentação estrutural da Bacia do Paraná: a questão dos lineamentos e sua influência na distribuição do Sistema Aquífero Guarani.

Geociências, São Paulo, v. 26, p. 297-311, 2008.

TUKEY, J. W. Exploratory data analysis. Reading, MA : Addison-Wesley, 1977.

WILDNER, W.; HARTMANN, L. A.; CUNHALOPES, R. A proposed stratigraphy for the Serra Geral Group in the Paraná Basin. In: MILANI, E.J., 
CHEMALE JR., F. (Ed.). Correlation Brazil-Africa. Gramado,RS: PETROBRAS, 2009.

ZALÁN, P. V.; WOLF, S.; CONCEIÇÃO, J. C. L.; ASTOLFI, A. M.; VIEIRA, I. S.; APPI, V. T.;

ZANOTTO O. A.; MARQUES A. Tectonics and Sedimentation of Paraná Basin. In:

INTERNATIONAL GONDWANA SYMPOSIUM, 7., 1991. Proocedings..., Tasmania, Austrália: [s.n.], 1991. p. $83-117$.

ZALÁN, P. V.; CONCEIÇÃO, J. C. J.; WOLFF, S.; ASTOLFI, M. A. M.; VIEIRA, I.S .; APPI, V. T.;
NETO, E. V. S.; CERQUEIRA, J. R.; ZANOTTO, O. A.;PAUMER, M. Análise da Bacia do Paraná. Rio de Janeiro: Petrobras, 1986. 1 v. ( Relatório Interno GT - OS - 009/25)- )

ZALÁN, P. V., WOLF, S., CONCEIÇÃO, J. C. DE J., MARQUES, A., ASTOLFI, M. A. M., VIEIRA, I. S., APPI, V. T., ZANOTTO, O. A. Bacia do Paraná. In: RAJA GABAGLIA, G. P., MILANI, E. J. (Eds.). Origem e evolução de bacias sedimentares. Rio de Janeiro: PETROBRÁS, 1990. p. 135-168. 